\title{
Extracellular proteolytic activities expressed by Bacillus pumilus isolated from endodontic and periodontal lesions
}

\author{
Blair T. Johnson, ${ }^{1,2} \dagger$ Lindsey N. Shaw, ${ }^{3,4}$ Daniel C. Nelson ${ }^{5}$ \\ and John A. Mayo ${ }^{1,3,6}$
}

Correspondence

John A. Mayo

jmayo@uga.edu

Received 6 November 2007

Accepted 5 February 2008
${ }^{1}$ Department of Microbiology, Immunology and Parasitology, School of Dentistry, Louisiana State University Health Sciences Center, New Orleans, LA 70119, USA

${ }^{2}$ Department of Endodontics, School of Dentistry, Louisiana State University Health Sciences Center, New Orleans, LA 70119, USA

${ }^{3}$ Department of Biochemistry and Molecular Biology, University of Georgia, Athens, GA 30602, USA

${ }^{4}$ Department of Biology, University of South Florida, Tampa, FL 33620, USA

${ }^{5}$ University of Maryland Biotechnology Institute, Center for Advanced Research in Biotechnology, Rockville, MD 20850, USA

${ }^{6}$ Department of Periodontics, School of Dentistry, Louisiana State University Health Sciences Center, New Orleans, LA 70119, USA

The purpose of the present study was to identify 12 Bacillus isolates that had been obtained from root canals of teeth requiring endodontic therapy and from periodontal pockets in severe marginal periodontitis, and to determine whether these isolates exhibited extracellular proteolytic activity and, using in vitro assays, whether any such activity could degrade substrates that would be pathophysiologically relevant with regard to the production of endodontic and periodontal lesions. Biochemical and carbohydrate fermentation patterns were used in the identification of all strains, which was confirmed by determination of the16S rRNA gene sequence for strain BJ0055.

Screening for production of extracellular proteolytic activity by all strains was done with a general proteinase substrate. All isolates were identified as representing Bacillus pumilus and all exhibited extracellular proteolytic activity. The putative pathophysiological relevance of extracellular proteinase production in strain BJ0055 was assessed using fluorophore-labelled elastin and collagen and several chromogenic peptides. Probable classes of proteinases acting on each substrate were investigated using class-specific inhibitors. Activity-pH profiles were determined in buffers at different $\mathrm{pH}$ values. Extracellular activities that were caseinolytic, elastinolytic, collagenolytic, glutamyl endopeptidase-like, and alanyl tripeptidyl peptidase-like were observed. No trypsin-like activities were detected. Serine- and chymotrypsin-like serine proteinase activities were detected, with activity observed at neutral and alkaline, but not acidic, $\mathrm{pH}$. B. pumilus strains isolated from endodontic and periodontal lesions exhibited extracellular activities that degrade elastin, collagen and other substrates. These activities may be virulence factors that contribute to tissue damage in apical periodontitis and severe marginal periodontitis.
tPresent address: Oral \& Maxillofacial Surgery Associates of Eau Claire, 1120 Oak Ridge Drive, Eau Claire, WI 54701, USA.

Abbreviations: AAPV, alanyl-alanyl-prolyl-valyl; BODIPY, 4,4-difluoro-5,7dimethyl-4-bora-3a,4a-diaza-s-indacene-3-propionic acid; DFP, di-isopropylfluorophosphate; E-64, L-trans-epoxysuccinyl-leucylamide-(4-guanidino)-butane; FL, phenylalanyl-leucyl; FLE, phenylalanyl-leucyl-glutamyl; FPA, phenylalanyl-prolyl-alanyl; GGL, glycyl-glycyl-leucyl; HPA, Hide Powder Azure; K, lysyl; L, leucyl; LTR, leucyl-threonyl-arginyl; MMP-1, matrix metalloproteinase 1 (tissue collagenase); OP, o-phenanthrolene; pNA, p-nitroanilide; R, arginyl; TLCK, tosyl lysyl chloromethyl ketone; TPCK, tosyl phenylalanyl chloromethyl ketone; TPPI, tripeptidyl-peptidase I; VLK, valyl-leucyl-lysyl.

\section{INTRODUCTION}

Apical and marginal periodontitis are diseases caused by a small subset of the approximately 700 microbial species that constitute the human oral microbiota (Paster et al., 2006). The predominant pathogens are Porphyromonas gingivalis, Tannerella forsythensis, Actinobacillus actinomycetemcomitans and Treponema denticola, although other organisms have been implicated as contributing or candidate pathogens (Socransky \& Haffajee, 1997; Holt \& Ebersole, 2005). Moreover, unusual micro-organisms may 
contribute to the aetiology of periodontitis (Helgason et al., 2000), especially if they elaborate virulence factors relevant to the disease process (Socransky, 1979).

Previously, we reported the isolation under aseptic surgical conditions of Bacillus spp. from periodontal pockets associated with severe marginal periodontitis and from root canals of teeth with necrotic pulps/apical periodontitis (Johnson et al., 1999). Bacillus species isolated from human oral samples have often been regarded as transient microflora (Marsh \& Martin, 1992) or as external contaminants due to careless handling of endodontic samples (Dahlen \& Moller, 1992). For these reasons, the genus Bacillus has received relatively little attention in oral microbiology. However, Bacillus species as suspected pathogens in dental plaque or oral lesions have been reported in a survey of collagenolytic activity of bacteria in dental plaque clinically associated with gingivitis or periodontitis (Soderling \& Paunio, 1981), from cases of apical periodontitis (Molander et al., 1998) and from marginal and apical periodontitis (Helgason et al., 2000). In the latter report it was suggested that virulent clones of Bacillus cereus and Bacillus thuringiensis might play a role in oral disease (Helgason et al., 2000).

It is apparent that Bacillus spp. are emerging opportunistic pathogens in oral disease. Therefore, the purpose of this study was (i) to identify the previously isolated Bacillus strains to the species level, and (ii) to determine whether these strains exhibited extracellular proteolytic activities capable of degrading components of periodontal tissues. Such activities may function as virulence factors in endodontic and periodontal infections.

\section{METHODS}

Identification, growth and characterization of Bacillus isolates. The selection of subjects, collection of clinical samples and bacterial isolation and initial characterization have all been described previously (Johnson et al., 1999), together with Institutional Review Board Approval and subject informed consent.

Putative Bacillus spp. isolated previously were endospore-forming Gram-positive rods (Johnson et al., 1999). In the present study, Bacillus isolates were identified by confirmation of Gram stain, cellular morphology and endospore formation, and by biochemical and carbohydrate fermentation patterns using API 20E and API 50 $\mathrm{CHB}$ kits used according to the manufacturer's instructions (bioMérieux). In addition, the identity of one isolate (BJ0055) was confirmed by sequencing the $16 \mathrm{~S}$ rRNA gene. Genomic DNA was prepared using a Qiagen DNeasy kit according to the manufacturer's instructions, with lysozyme serving as the lytic agent. This was then used as template for an AccumPrime PFX (Invitrogen) PCR reaction with the primer pair OL398 (5' ${ }^{\prime}$-TCCTACGGGAGGCAGCAGT-3') and OL399 (5'-GGACTACCAGGGTATCTAATCCTGTT-3'), described originally by Nadkarni et al. (2002), resulting in a product of approximately $550 \mathrm{bp}$. This fragment was purified by gel extraction using a Qiaquick gel extraction kit (Qiagen), according to the manufacturer's protocol, before being cloned into pCR2.1 using a TOPO TA cloning kit (Invitrogen), creating construct pLES226. The cloned insert was then sequenced (University of Georgia Integrated Biotech Laboratories) using the M13 forward and reverse primers, the target sequences of which are located immediately upstream and downstream, respectively, of the pCR2.1 multiple cloning site. The sequence was subjected to BLAST analysis (www.ncbi.nlm.nih.gov).

Cultures were grown in tryptic soy broth with glucose (TSBG; Difco) or in a semi-defined medium (modified FMC; MFMC) based on that of Terleckyj et al. (1975) and containing (per litre): $20 \mathrm{~g}$ D-glucose, $6 \mathrm{~g} \mathrm{NaC} \mathrm{H}_{3} \mathrm{O}_{2} .3 \mathrm{H}_{2} \mathrm{O}, 600 \mathrm{mg}$ ammonium sulfate, $10 \mathrm{mg} \mathrm{NaCl}$, $440 \mathrm{mg} \quad \mathrm{KH}_{2} \mathrm{PO}_{4}, 300 \mathrm{mg} \quad \mathrm{K}_{2} \mathrm{HPO}_{4}, 3.15 \mathrm{~g} \quad \mathrm{Na}_{2} \mathrm{HPO}_{4}, 2.05 \mathrm{~g}$ $\mathrm{NaH}_{2} \mathrm{PO}_{4} \cdot \mathrm{H}_{2} \mathrm{O}, 225 \mathrm{mg} \mathrm{NaC} \mathrm{H}_{5} \mathrm{O}_{7} \cdot 2 \mathrm{H}_{2} \mathrm{O}, 200 \mathrm{mg}$ L-cysteine, $2.5 \mathrm{~g}$ $\mathrm{Na}_{2} \mathrm{CO}_{3}, 5.0 \mathrm{~g}$ acid-hydrolysed casein, $1.0 \mathrm{~g}$ enzymic digest of casein, 1.0 g yeast extract, $10 \mathrm{mg} \mathrm{FeSO} 4.7 \mathrm{H}_{2} \mathrm{O}, 20 \mathrm{mg} \mathrm{MgSO}{ }_{4} .7 \mathrm{H}_{2} \mathrm{O}, 10 \mathrm{mg}$ $\mathrm{MnSO}_{4}, 35 \mathrm{mg}$ adenine, $27 \mathrm{mg}$ guanine, and $30 \mathrm{mg}$ uracil. The $\mathrm{pH}$ was adjusted to 7.8 and the medium was filter-sterilized. In preliminary experiments, cultures were grown for $24-48 \mathrm{~h}$ at $37{ }^{\circ} \mathrm{C}$ aerobically with shaking, and in $5-10 \% \mathrm{CO}_{2}$ in air (static) or anaerobically (static).

Detection and preliminary characterization of extracellular proteolytic activities. Growth and the presence of extracellular proteolytic activity were observed in both TSBG and MFMC and under all growth conditions, with the greatest proteolytic activity in shaken aerobic cultures (data not shown). Subsequent experiments were all done with shaken aerobic cultures. Unconcentrated culture supernatants of all strains (grown in TSBG) were screened for the presence of extracellular proteolytic activity essentially as described by Makinen \& Makinen (1987), using the general proteinase substrate Hide Powder Azure (HPA; Calbiochem) at $10 \mathrm{mg} \mathrm{ml}^{-1}$ (Rinderknecht et al., 1968). Complete digestion of HPA $\left(1 \mathrm{mg} \mathrm{ml}^{-1}\right)$ yielded an $A_{595}$ of 0.30 (data not shown). Strain BJ0055 showed the greatest proteolytic activity and was selected for further characterization. Bacillus pumilus BJ0055 was grown in MFMC and culture fluids were collected by centrifugation. The culture fluids were then passed through membrane filters $(0.45 \mu \mathrm{m}$ pore size $)$ and concentrated 300 fold by ultrafiltration ( $3 \mathrm{kD}$ cut-off).

Concentrated culture fluids were screened for proteolytic activity against a variety of fluorogenic and chromogenic substrates. Fluorescein-labelled type IV collagen and BODIPY (4,4-difluoro5,7-dimethyl-4-bora-3a,4a-diaza-s-indacene-3-propionic acid)-conjugated casein and elastin were obtained from Molecular Probes and were assayed according to the manufacturer's instructions (www.probes.invitrogen.com) using a Gemini EM microplate fluorometer (Molecular Devices) at $37^{\circ} \mathrm{C}$. Briefly, enzyme and buffer ( $50 \mathrm{mM}$ Tris/10 mM NaCl, $\mathrm{pH}$ 7.9) were pre-incubated in microplate wells for $10 \mathrm{~min}$ at $37^{\circ} \mathrm{C}$, after which the reaction was started by the addition of substrate. Data were collected in the kinetics mode. Instrument settings were excitation $495 \mathrm{~nm}$ and emission $515 \mathrm{~nm}$ for collagen and excitation $485 \mathrm{~nm}$, emission $514 \mathrm{~nm}$ and cut-off $495 \mathrm{~nm}$ for casein and elastin.

Chromogenic substrates used were amino acid- or peptide- $p$ nitroanilides ( $p$ NAs) obtained from Bachem or Sigma. Substrates with blocked amino-termini included R (arginyl), FL (phenylalanyl-leucyl), FLE (phenylalanyl-leucyl-glutamyl), GGL (glycyl-glycyl-leucyl) and AAPV (alanyl-alanyl-prolyl-valyl). Substrates with free amino-termini included K (lysyl), L (leucyl), FPA (phenylalanyl-prolyl-alanyl), VLK (valyl-leucyl-lysyl), and LTR (leucyl-threonyl-arginyl).

Assays for chromogenic substrates were performed as described for fluorogenic substrates but using a SpectraMax Plus microplate spectrophotometer (Molecular Devices) at $37^{\circ} \mathrm{C}$. Reactions were started by addition of substrate $(0.2 \mathrm{mM}$ final concentration), and absorbance at $405 \mathrm{~nm}\left(A_{405}\right)$ was recorded.

Types of proteolytic activities were assessed by use of class-specific inhibitors (Beynon \& Salvesen, 1989). Inhibitors were obtained from Bachem, Boehringer Mannheim or Sigma. The inhibitors and their target proteinase classes are shown in Tables 1 and 2. Assays were run 
Table 1. Extracellular proteolytic activity of $B$. pumilus BJ0055: digestion of fluorophore-conjugated proteins and its inhibition by class-specific inhibitors

Results are representative of several assays run on different days and with different batches of concentrated culture fluids. Abbreviations: DFP, di-isopropylfluorophosphate; E-64, L-trans-epoxysuccinyl-leucylamide-(4-guanidino)-butane; OP, o-phenanthroline; TLCK, tosyl lysyl chloromethyl ketone; TPCK, tosyl phenylalanyl chloromethyl ketone. NAD, No activity detected in the presence of inhibitor; ND, not done.

\begin{tabular}{|c|c|c|c|c|}
\hline \multirow[t]{2}{*}{ Inhibitor } & \multirow[t]{2}{*}{ Target proteinase } & \multicolumn{3}{|c|}{ Relative activity on: } \\
\hline & & Casein & Elastin & Collagen \\
\hline None & - & $1.000^{\star}$ & 1.000 & 1.000 \\
\hline \multicolumn{5}{|l|}{ DFP } \\
\hline $0.5 \mathrm{mM}$ & Serine & NAD & 0.202 & NAD \\
\hline $5 \mathrm{mM}$ & & NAD & 0.148 & NAD \\
\hline \multicolumn{5}{|l|}{ TLCK } \\
\hline $10 \mu \mathrm{M}$ & Trypsin-like serine & 0.989 & 1.061 & ND \\
\hline $100 \mu \mathrm{M}$ & & 1.035 & 1.066 & ND \\
\hline \multicolumn{5}{|c|}{ Chymostatin } \\
\hline $100 \mu \mathrm{M}$ & $\begin{array}{l}\text { Chymotrypsin-like } \\
\text { serine }\end{array}$ & 0.796 & 0.239 & NAD \\
\hline $500 \mu \mathrm{M}$ & & 0.922 & 0.208 & NAD \\
\hline \multicolumn{5}{|l|}{ ТPCK } \\
\hline $10 \mu \mathrm{M}$ & $\begin{array}{l}\text { Chymotrypsin-like } \\
\text { serine }\end{array}$ & 1.127 & 0.908 & ND \\
\hline $100 \mu \mathrm{M}$ & & 1.196 & 0.561 & ND \\
\hline \multicolumn{5}{|l|}{$\mathrm{OP}$} \\
\hline $2 \mathrm{mM}$ & $\begin{array}{l}\text { Metallo-, } \\
\text { metal-activated }\end{array}$ & 1.056 & 0.865 & 0.742 \\
\hline $10 \mathrm{mM}$ & & 1.032 & 0.750 & 1.151 \\
\hline \multicolumn{5}{|l|}{ EDTA } \\
\hline $2.5 \mathrm{mM}$ & $\begin{array}{l}\text { Metallo-, } \\
\text { metal-activated }\end{array}$ & 1.041 & 0.875 & 1.081 \\
\hline $10 \mathrm{mM}$ & & 1.004 & 0.735 & 0.904 \\
\hline \multicolumn{5}{|l|}{ E-64 } \\
\hline $1 \mu \mathrm{M}$ & Cysteine & 1.015 & 0.935 & 1.240 \\
\hline $10 \mu \mathrm{M}$ & & 1.001 & 0.860 & 1.413 \\
\hline \multicolumn{5}{|l|}{ Pepstatin } \\
\hline $1 \mu \mathrm{M}$ & Aspartic & 0.970 & 0.840 & 1.093 \\
\hline $10 \mu \mathrm{M}$ & & 1.272 & 1.125 & 0.940 \\
\hline \multicolumn{5}{|l|}{ Bestatin } \\
\hline $5 \mu \mathrm{M}$ & Alanyl aminopeptidase & 1.244 & 1.165 & 1.109 \\
\hline $50 \mu \mathrm{M}$ & & 1.301 & 1.190 & 1.004 \\
\hline
\end{tabular}

*Values corresponding to relative activity $=1.000$, in RFU (relative fluorescence units) $\min ^{-1}$ : casein, $1.87 \times 10^{5}$; elastin, $2.00 \times 10^{6}$; collagen, $2.42 \times 10^{6}$.

as described for fluorogenic and chromogenic substrates, with enzyme and inhibitor pre-incubated in buffer before addition of substrate. In preliminary experiments it was observed that methanol, the solvent for $o$-phenanthrolene (OP), by itself inhibited proteolytic activity (data not shown). All OP results were corrected for this effect by use of appropriate controls.
Table 2. Extracellular proteolytic activity of $B$. pumilus BJ0055: hydrolysis of peptide-pNA substrates and its inhibition by class inhibitors

Results are representative of several assays run on different days and with different batches of concentrated culture fluids. Abbreviations: AAPV, elastase-like; DFP, di-isopropylfluorophosphate; GGL, chymotrypsin-like; FLE, glutamyl endopeptidase; FPA, alanyl tripeptidyl peptidase; TLCK, tosyl lysyl chloromethyl ketone; TPCK, tosyl phenylalanyl chloromethyl ketone; E-64, L-trans-epoxysuccinyl-leucylamide-(4-guanidino)-butane. NAD, No activity detected in the presence of inhibitor.

\begin{tabular}{|c|c|c|c|c|c|}
\hline \multirow[t]{2}{*}{ Inhibitor } & \multirow[t]{2}{*}{ Target proteinase } & \multicolumn{4}{|c|}{ Relative activity on: } \\
\hline & & AAPV & GGL & FLE & FPA \\
\hline None & - & $1.000^{*}$ & 1.000 & 1.000 & 1.000 \\
\hline \multicolumn{6}{|l|}{ DFP } \\
\hline $0.5 \mathrm{mM}$ & Serine & NAD & $\mathrm{NAD}$ & 0.024 & 0.570 \\
\hline $5 \mathrm{mM}$ & & NAD & $\mathrm{NAD}$ & $\mathrm{NAD}$ & 0.569 \\
\hline \multicolumn{6}{|l|}{ TLCK } \\
\hline $10 \mu \mathrm{M}$ & Trypsin-like serine & 0.990 & 0.996 & 1.010 & 1.037 \\
\hline $100 \mu \mathrm{M}$ & & 0.949 & 0.991 & 1.007 & 1.030 \\
\hline \multicolumn{6}{|c|}{ Chymostatin } \\
\hline $100 \mu \mathrm{M}$ & $\begin{array}{l}\text { Chymotrypsin-like } \\
\text { serine }\end{array}$ & 0.025 & $\mathrm{NAD}$ & 0.742 & 0.518 \\
\hline $500 \mu \mathrm{M}$ & & 0.040 & 0.192 & 0.631 & 0.382 \\
\hline \multicolumn{6}{|l|}{ TPCK } \\
\hline $10 \mu \mathrm{M}$ & $\begin{array}{l}\text { Chymotrypsin-like } \\
\text { serine }\end{array}$ & 0.934 & 0.899 & 1.012 & 0.884 \\
\hline $100 \mu \mathrm{M}$ & & 0.017 & $\mathrm{NAD}$ & 0.852 & 0.464 \\
\hline \multicolumn{6}{|l|}{$\mathrm{OP}$} \\
\hline $2 \mathrm{mM}$ & $\begin{array}{l}\text { Metallo-, } \\
\text { metal-activated }\end{array}$ & 0.710 & 1.000 & 0.988 & 0.650 \\
\hline $10 \mathrm{mM}$ & & 0.784 & 0.477 & 1.000 & 0.488 \\
\hline \multicolumn{6}{|l|}{ EDTA } \\
\hline $2.5 \mathrm{mM}$ & $\begin{array}{l}\text { Metallo-, } \\
\text { metal-activated }\end{array}$ & 0.964 & 1.036 & 0.735 & 1.080 \\
\hline $10 \mathrm{mM}$ & & 0.969 & 1.154 & 0.618 & 1.035 \\
\hline \multicolumn{6}{|l|}{ E-64 } \\
\hline $1 \mu \mathrm{M}$ & Cysteine & 1.096 & 1.178 & 0.909 & 1.117 \\
\hline $10 \mu \mathrm{M}$ & & 1.168 & 1.070 & 0.957 & 1.125 \\
\hline \multicolumn{6}{|l|}{ Pepstatin } \\
\hline $1 \mu \mathrm{M}$ & Aspartic & 1.101 & 1.141 & 0.896 & 1.117 \\
\hline $10 \mu \mathrm{M}$ & & 0.963 & 1.059 & 1.037 & 1.184 \\
\hline \multicolumn{6}{|l|}{ Bestatin } \\
\hline $5 \mu \mathrm{M}$ & $\begin{array}{l}\text { Alanyl } \\
\text { aminopeptidase }\end{array}$ & 1.101 & 0.974 & 0.992 & 1.133 \\
\hline $50 \mu \mathrm{M}$ & & 1.090 & 1.162 & 1.021 & 1.176 \\
\hline
\end{tabular}

${ }^{*}$ Values corresponding to relative activity $=1.000$, in $\mathrm{m}_{405} \mathrm{~min}^{-1}$ : AAPV, 29.8; GGL, 25.0; FLE, 71.8; FPA, 36.5.

Proteolytic activity as a function of $\mathbf{p H}$. The dependence of BODIPY-elastin- and FPA-pNA-digesting activities on $\mathrm{pH}$ was assessed by running assays as described above in buffers with various $\mathrm{pH}$ values. Citrate/phosphate buffer was used for $\mathrm{pH} 3-6$, Tris for $\mathrm{pH}$ 7-9 and CAPS for $\mathrm{pH} 10-11$. 


\section{RESULTS AND DISCUSSION}

\section{Identification and characterization of Bacillus isolates}

In the present study, all 12 isolates were confirmed as belonging to the genus Bacillus (Gram-positive, facultatively anaerobic, endospore-forming rods) and were identified as representing $B$. pumilus using biochemical and carbohydrate fermentation patterns. Strains were identified based on hydrolysis of gelatin and the $\beta$ galactosidase substrate ONPG, the production of acetoin and use of citrate, the inability to hydrolyse starch or to reduce nitrate to nitrite, and fermentation of tagatose and gentiobiose but not turanose, sorbitol or galactose (data not shown). These characteristics are consistent with $B$. pumilus (Logan \& Berkeley, 1984). Furthermore, BLAST sequence analysis revealed that the $536 \mathrm{bp}$ fragment contained within pLES226 and representing the $16 \mathrm{~S}$ rRNA gene of strain BJ0055 matched exactly, without mistake, the sequence of the 16S rRNA gene of the type strain of B. pumilus, ATCC $7601^{\mathrm{T}}$ (www.ncbi.nlm.nih.gov) (data not shown).

Bacillus anthracis has long been known to be a major human pathogen (Xu \& Frucht, 2007). Other members of the genus are regarded as opportunistic pathogens causing endopthalmitis after penetrating eye injuries, food poisoning and, in compromised patients, bacteraemia, septicaemia, endocarditis, and central nervous system or respiratory infections (Callegan et al., 1999; Ewald et al., 2006; Granum \& Lund, 1997; Banerjee et al., 1988; Drobniewski, 1993; Tuazon et al., 1979). B. pumilus can also be a systemic pathogen, causing bacteraemia in neutropenic patients and producing an allergen involved in allergic pneumonitis in machinists (Banerjee et al., 1988; Bernstein et al., 1995; Tuazon et al., 1979). Additionally, B. pumilus has been found in the intestinal flora of humans (Vann et al., 1976) and B. pumilus strains have been shown to produce exotoxins that are cytotoxic for cultured mammalian cells (Brophy \& Knoop, 1982; Hoult \& Tuxford, 1991). Furthermore, this organism can produce clindamycin-associated enterocolitis in guinea-pigs (Brophy \& Knoop, 1982).

Members of the genus Bacillus as oral pathogens have received little attention, having been regarded as contaminants when isolated from endodontic or other oral samples (Dahlen \& Moller, 1992; Marsh \& Martin, 1992). However, in more recent reports of Bacillus isolates from marginal and periapical sites, carefully controlled clinical and sampling procedures made such contamination unlikely (Johnson et al., 1999; Sunde et al., 2000, 2002). Thus it is probable that such Bacillus isolates are in fact part of the microbiota of the lesion. It has been postulated that the presence of unusual organisms in such lesions suggests an aetiological role (Helgason et al., 2000), and a number of Bacillus isolates from periodontal and endodontic lesions have been reported. These include 12
Bacillus isolates from marginal and periapical periodontitis (Johnson et al., 1999), one Bacillus sp. isolated from a series of endodontic samples (Molander et al., 1998), seven Bacillus spp. including B. pumilus from another series (Sunde et al., 2002), and 20 B. cereus and B. thuringiensis isolates from periodontal and periapical lesions (Helgason et al., 2000). In an earlier study, $15 \%$ of apical periodontitis samples contained $B$. pumilus, with numbers as high as approximately $0.7 \%$ of the total viable count (Johnson et al., 1999). We propose that members of the genus Bacillus that were isolated carefully from oral disease sites are legitimate isolates and potential oral pathogens.

\section{Detection and characterization of extracellular proteolytic activities}

Cell-free culture fluids from all 12 oral strains of B. pumilus exhibited proteolytic activity that degraded the general proteinase substrate HPA. The mean rate was $3.88 \mathrm{mg}$ HPA ml ${ }^{-1} \mathrm{~h}^{-1}$ (range 1.03-5.30) (data not shown). The highest activity was seen with strain BJ0055, which was used for all subsequent experiments.

Extracellular proteolytic activities in concentrated culture fluids of B. pumilus BJ0055 degraded various protein (Table 1) and peptide (Table 2) substrates. In Table 1, caseinolytic activity was inhibited by di-isopropylfluorophosphate (DFP) and therefore is a serine proteinase, whereas elastinolytic and collagenolytic activities involve chymotrypsin-like serine proteinases that are inhibited by both DFP and chymostatin. This was confirmed for elastinolytic activity, which was also inhibited by tosyl phenylalanyl chloromethyl ketone (TPCK; Table 1); collagenolytic activity was not tested with TPCK. No other classes of caseinolytic, elastinolytic or collagenolytic activity were observed.

Table 2 shows the hydrolysis of various $p \mathrm{NA}$-conjugated peptides that were used as convenient proteinase or peptidase substrates. Activities representing elastase-like (AAPV-pNA-hydrolysing) and chymotrypsin-like (GGLpNA-hydrolysing) enzymes, glutamyl endopeptidase (FLEpNA-hydrolysing), and alanyl tripeptidyl peptidase (FPApNA-hydrolysing) were observed. No leucine peptidase or trypsin-like activities were detected, as indicated by the failure to hydrolyse the following relevant peptide- $p$ NA substrates: L (leucine aminopeptidase-like); FL (leucine endopeptidase-like); K, VLK, R and LTR (trypsin-like enzymes). The absence of trypsin-like activities was further indicated by the lack of inhibition by tosyl lysyl chloromethyl ketone (TLCK; Tables 1 and 2). In addition, no aminopeptidases other than alanyl tripeptidyl peptidase were detected. No pNA substrates with a free aminoterminus, other than FPA, were hydrolysed.

Glutamyl endopeptidase activity was inhibited by DFP and therefore is a serine proteinase, whereas elastase- and GGLpNA-hydrolysing activities are chymotrypsin-like serine 

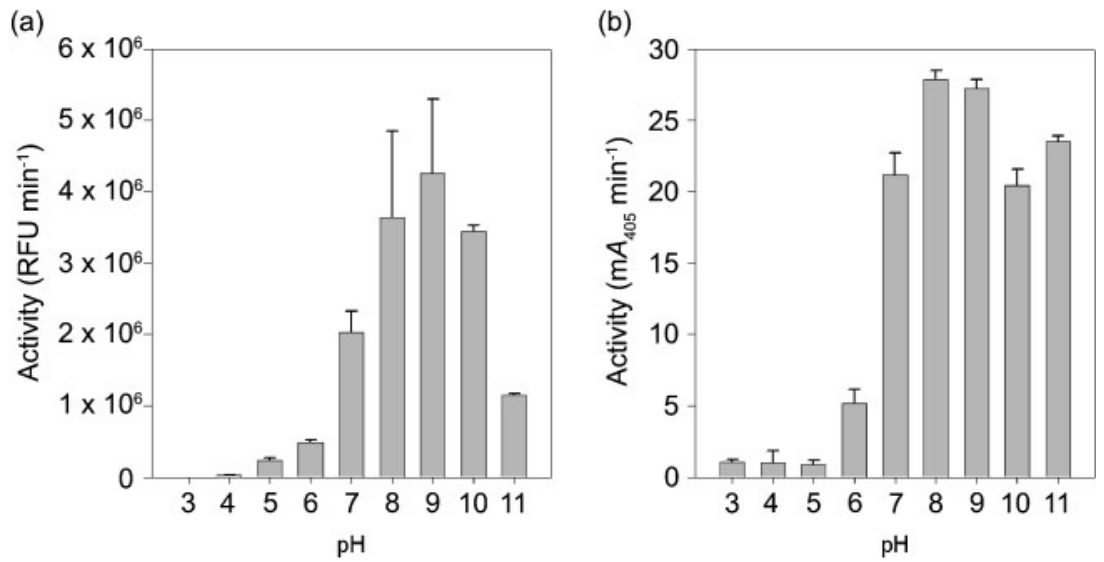

Fig. 1. Effect of $\mathrm{pH}$ on extracellular elastinolytic (a) and alanyl tripeptidyl peptidase (b) activities. Assays were run in triplicate and results are expressed as means $\pm \mathrm{SD}$.

proteinases that are inhibited by DFP, chymostatin and TPCK. This inhibition by DFP, chymostatin and TPCK was virtually complete for both activities, as was the DFP inhibition of glutamyl endopeptidase. The GGL-pNAhydrolysing chymotrypsin-like activity may be metal activated or stabilized as it was slightly inhibited by $10 \mathrm{mM}$ OP. No other classes of elastase-like, chymotrypsinlike- or glutamyl endopeptidase activities were observed. In contrast to results for elastase- and chymotrypsinlike activities and glutamyl endopeptidase, inhibition of alanyl tripeptidyl peptidase showed both chymotrypsinlike serine- and metallo-proteinase characteristics with incomplete inhibition by DFP, chymostatin, TPCK or OP.

Gingival crevicular fluid is approximately neutral in $\mathrm{pH}$ in good oral health and becomes more alkaline $(\mathrm{pH} 8.5)$ as periodontitis develops (Bickel \& Cimasoni, 1985). Accordingly, it was of interest to examine the modulation of selected activities by $\mathrm{pH}$. The effects of $\mathrm{pH}$ on elastinolytic and alanyl tripeptidyl peptidase activities are shown in Fig. 1. It is important to note that both substrates were stable under all conditions of $\mathrm{pH}$, temperature, time and assay buffer used in these experiments (data not shown). Furthermore, fluorescence of the elastin substrate is insensitive to $\mathrm{pH}$ as the BODIPY reporter contains no ionizable groups (Jones et al., 1997). Thus, the results shown in Figs 1 and 2 are not attributable to $\mathrm{pH}$ effects on substrates.

Elastinolytic activity (Fig. 1a) peaked at $\mathrm{pH} 9$ with substantial activities at $\mathrm{pH} 8$ and 10 , consistent with neutral/alkaline proteinase activity. The $\mathrm{pH}$ profile for alanyl tripeptidyl peptidase activity (Fig. 1b) was broad, peaking at $\mathrm{pH} 8$ and 9 with substantial activity from $\mathrm{pH} 7$ to 11. This may represent a mixture of activities. Acid proteinase activities were not detected for either substrate. These results suggest that the elastinolytic and alanyl tripeptidyl peptidase activities could be active in situ at the elevated $\mathrm{pH}$ of periodontitis lesions, as high as 8.5 (Bickel \& Cimasoni, 1985). Activity at $\mathrm{pH} 11$ is unlikely to be pathophysiologically important in periodontitis. However, it probably does represent part of the array of proteinases exhibited by B. pumilus, some of which retain activity even at pH 12 and 13 (Kumar, 2002; Miyaji et al., 2006).

The broad $\mathrm{pH}$ activity profile of alanyl tripeptidyl peptidase (FPA- $p$ NA hydrolysing) and its partial inhibition by serine- and metallo-class inhibitors suggested a mixture of activities. This concept was investigated using mixed inhibitor studies at $\mathrm{pH} 9$ and 11. The results for inhibition of alanyl tripeptidyl peptidase activity by mixtures of DFP (a)

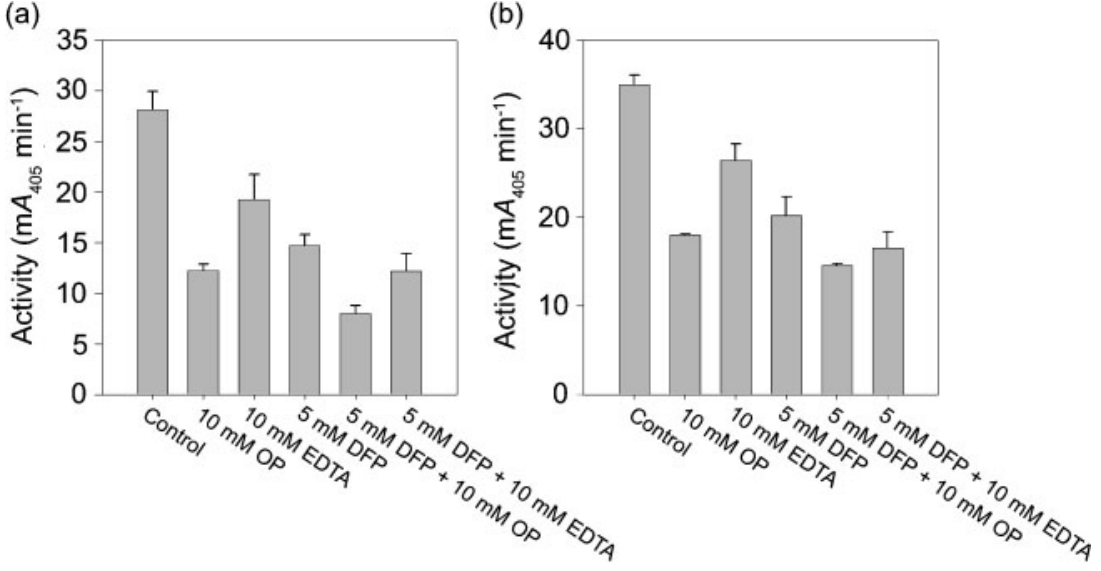

Fig. 2. Effects of mixed inhibitors on alanyl tripeptidyl peptidase activity at $\mathrm{pH} 9$ (a) and 11 (b). Assays were run in triplicate, and results are expressed as means \pm SD. DFP, Di-isopropylflurophosphate; OP, o-phenanthrolene. 
and either OP or EDTA at pH 9 and 11 are shown in Fig. 2a and $b$, respectively. Inhibition by mixtures of DFP and either OP or EDTA was greater than that for any of these inhibitors alone, at both $\mathrm{pH}$ values. However, $30-40 \%$ of total activity was still resistant even to these combinations of inhibitors.

Bacterial proteinases, lipases and haemolysins are considered to be virulence factors (Drobniewski, 1993; Travis et al., 1995, 1997), and members of the genus Bacillus are noted for the production of extracellular forms of such activities (Gupta et al., 2002; Logan \& Berkeley, 1984; Priest, 1985). In view of the proteolytic properties of the $B$. pumilus strains as described in the present study, proteinases are of particular interest. The potential of proteinases as virulence factors in periodontitis and in systemic disease has been recognized (Travis et al., 1995, 1997; Xu \& Frucht, 2007), with sites of action in the host including cytokines, collagen, clotting factors, immunoglobulins, extracellular matrix proteins, cell-surface receptors and disruption of signal transduction.

The B. pumilus strains isolated in this study exhibited an extracellular activity that extensively degraded the general proteinase substrate HPA (data not shown). An extracellular proteinase from an oral strain of $B$. cereus has been purified and characterized as a true metalloenzyme collagenase similar to that produced by Clostridium histolyticum (Makinen \& Makinen, 1987; Soderling \& Paunio, 1981). Such activities have been implicated as virulence factors contributing to the initiation and progression of endodontic and periodontal lesions (Johnson et al., 1999; Travis et al., 1995, 1997).

As exemplified by strain BJ0055, oral isolates of B. pumilus also exhibit extracellular proteolytic activities that result in the degradation of a number of protein and peptide substrates. The results shown in Fig. 1 illustrate neutral and alkaline activities degrading elastin and FPA-pNA. Collagen and elastin, as well as the general substrate casein, were digested at neutral $\mathrm{pH}$ (Table 1) and collagenolysis and elastinolysis are part of the tissue destruction seen in marginal and periapical periodontitis. In addition to these activities, chymotrypsin-, glutamyl endopeptidase- and alanyl tripeptidyl peptidase-like activities were found (Table 2). While extracellular subtilisin- and glutamyl endopeptidase-like activities are typical of members of the genus Bacillus (Gupta et al., 2002; Kakudo et al., 1992; Leshchinskaya et al., 1997; Priest, 1985), chymotrypsin-like activity in the genus Bacillus has been observed infrequently (Aoyama et al., 2000; Kato et al. 1992). Furthermore, when observed it has been described as subtilisin-like rather than chymotrypsin-like. For example, Aoyama et al. (2000) mischaracterized a soy-milk-coagulating enzyme from $B$. pumilus as 'subtilisin-like' despite its complete inhibition by chymostatin. Similarly, a chymostatin-inhibited serine proteinase from Bacillus subtilis was also described as subtilisinlike (Kato et al., 1992). Chymostatin is not known to be an inhibitor of subtilisin (Ballinger \& Wells, 1998), but does target chymotrypsin-like serine proteinases (Beynon \& Salvesen, 1989).

Furthermore, alanyl tripeptidyl peptidase-like activity is an unexpected finding. This activity, also known as tripeptidyl-peptidase I (TPPI) (Golabek \& Kida, 2006; McDonald, 1998), is brought about by an aminopeptidase that can act on tripeptides with free amino-termini including FPA- $p$ NA (Rawlings et al., 2006). It is found in mammalian neuronal tissue, where enzyme deficiency leads to neurodegenerative disease (Golabek \& Kida, 2006). Whereas the mammalian activity is due to an acidic peptidase (Golabek \& Kida, 2006; McDonald, 1998), the B. pumilus activity has neutral/ alkaline characteristics (Figs 1 and 2). With the exception of the alanyl tripeptidyl peptidase-like activity, the activities reported in Tables 1 and 2 were serine- or chymotrypsinlike serine-class proteolytic activities. Such extracellular proteinases have been observed previously in the genus Bacillus (Gupta et al., 2002; Kato et al., 1992; Leshchinskaya et al., 1997; Priest, 1985), including B. pumilus (Aoyama et al., 2000; Fabian, 1970; Kumar, 2002; Miyaji et al., 2006; Tran-Chau \& Urbanek, 1974).

In contrast to these typical Bacillus extracellular proteinases, approximately $40 \%$ of the alanyl tripeptidyl peptidase-like activity was resistant to high concentrations of serine or metallo-proteinase inhibitors, alone (Table 2) or in combination (Fig. 2). Furthermore, this activity was totally resistant to class inhibitors of cysteine and aspartic proteinases and alanyl aminopeptidases (Table 2). Thus, this activity is partially or totally resistant to inhibitors of the four major classes of proteinases and to an inhibitor of a highly relevant group of aminopeptidases.

This is a puzzling result as typical Bacillus extracellular neutral and alkaline proteinases belong to serine or metallo classes (Gupta et al., 2002; Miyaji et al., 2006; Priest, 1985). Mammalian TPPI is also resistant to inhibition by DFP and belongs to the sedolisin family of serine-carboxypeptidases with greatest activity at acid pH (Golabek \& Kida, 2006; Kakudo et al., 1992). However, the B. pumilus activity was virtually devoid of activity at $\mathrm{pH}$ values below 6 (Fig. 1b). Furthermore, the B. pumilus activity was not inhibited by bestatin, a classical inhibitor of alanyl aminopeptidases (Table 2; Beynon \& Salvesen, 1989). Thus, the bestatinDFP-EDTA-OP-resistant portion of the B. pumilus extracellular alanyl tripeptidyl peptidase activity could represent a novel enzyme, although the total activity probably consists of a mixture of activities with differing $\mathrm{pH}$ optima and inhibitor sensitivities. However, it should be noted that all proteolytic activities described here were observed in crude culture fluid concentrates. Proper and complete characterization of these activities will require that the individual enzymes be purified.

To summarize, these results suggest that B. pumilus BJ0055 exhibits at least three extracellular proteolytic activities, a caseinolytic serine proteinase, an elastin-degrading chymotrypsin-like enzyme and an alanyl tripeptidyl peptidase-like activity. Other activities may be related to these. The 
DFP-sensitive, chymostatin- and TPCK-resistant caseinolytic activity may be subtilisin-like (Ballinger \& Wells, 1998; Nonaka et al., 2004), as also may the glutamyl endopeptidase-like activity. Its inhibitor profile is similar to that of the caseinolytic activity, and an analogous enzyme from Bacillus intermedius uses both FLE-pNA and casein as substrates (Leshchinskaya et al., 1997). The chymotrypsinlike elastinolytic activity has inhibitor sensitivities and a $\mathrm{pH}$ profile in common with a soybean-milk-coagulating activity from $B$. pumilus that was described by Aoyama et al. (2000); the AAPV- and GGL-pNA-degrading activities also share this inhibitor sensitivity profile. An alkaline protease purified from $B$. pumilus by Kumar (2002) had a broad $\mathrm{pH}$ profile with highest activity at $\mathrm{pH}$ 9-12, attacked di-, tri- and tetra-peptide-pNA substrates, required a free amino-terminus on the peptide, and preferred alanine or phenylalanine in the $\mathrm{P} 1$ position of the peptide. These properties are similar to those of the alanyl tripeptidyl peptidase-like activity in the present study.

\section{Possible interactions of proteinases and peptidases from oral bacteria and host in the pathogenesis of periodontitis}

Collagen and elastin are major components of the structure of the periodontium (Chavrier, 1990; Crouch \& Bornstein, 1978; Rosenbloom et al., 1993), and destruction of periodontal tissue is one of the obvious manifestations of periodontitis. Fig. 3 shows a scheme in which the proteolytic activities of oral bacteria including $B$. pumilus might act in concert with host proteinases and peptidases to degrade collagen and elastin. The roles of tissue collagenase (matrix metalloproteinase 1; MMP-1) and neutrophil elastase in periodontal disease are well known
(Eley \& Cox, 1992; Harrington, 1996; Loos \& Tjoa, 2005). Furthermore, native collagen and elastase have non-fibrillar or less ordered regions that can be accessible to bacterial collagenolytic and elastinolytic activities that are not true collagenases or elastases (Harrington, 1996). These activities could produce nicks or gaps that might be access points, or larger peptides that might be substrates, for other bacterial activities such as the GGL-pNA-hydrolysing- and glutamyl endopeptidase-like activities observed here. Products of these reactions in turn could serve as substrates for alanyl tripeptidyl peptidase and other bacterial and host peptidases, ultimately reducing collagen and elastin to amino acids and small peptides.

This scheme is supported by several points. First, in fibroblast and gingival lamina propria models, elastin peptides upregulate the production of MMP-1 and downregulate the production of tissue inhibitors of matrix proteinases (Cozlin et al., 2006; Duca et al., 2002). Thus, it is possible that elastinolysis by bacterial or host proteinases may have a double effect in the destruction of periodontal tissue, by directly degrading periodontal extracellular matrix material and by in effect enhancing or driving collagenolysis by host enzymes. Second, elastin (Debelle \& Tamburro, 1999) and collagen (Crouch \& Bornstein, 1978; Swann \& Sotman, 1980) both contain substantial amounts of alanine, as much as 50-100 alanines per 1000 amino acid residues. Therefore, elastinolysis and collagenolysis are likely to yield alanyl peptide substrates for alanyl tripeptidyl peptidase. Third, a bone resorption study suggested that mammalian TPPI participated in bone resorption and that collagen was one of its natural substrates (Golabek \& Kida, 2006). Thus, it is reasonable to suggest that bacterial and host proteinases, acting in concert, can play a key role in tissue destruction in apical and marginal periodontitis.

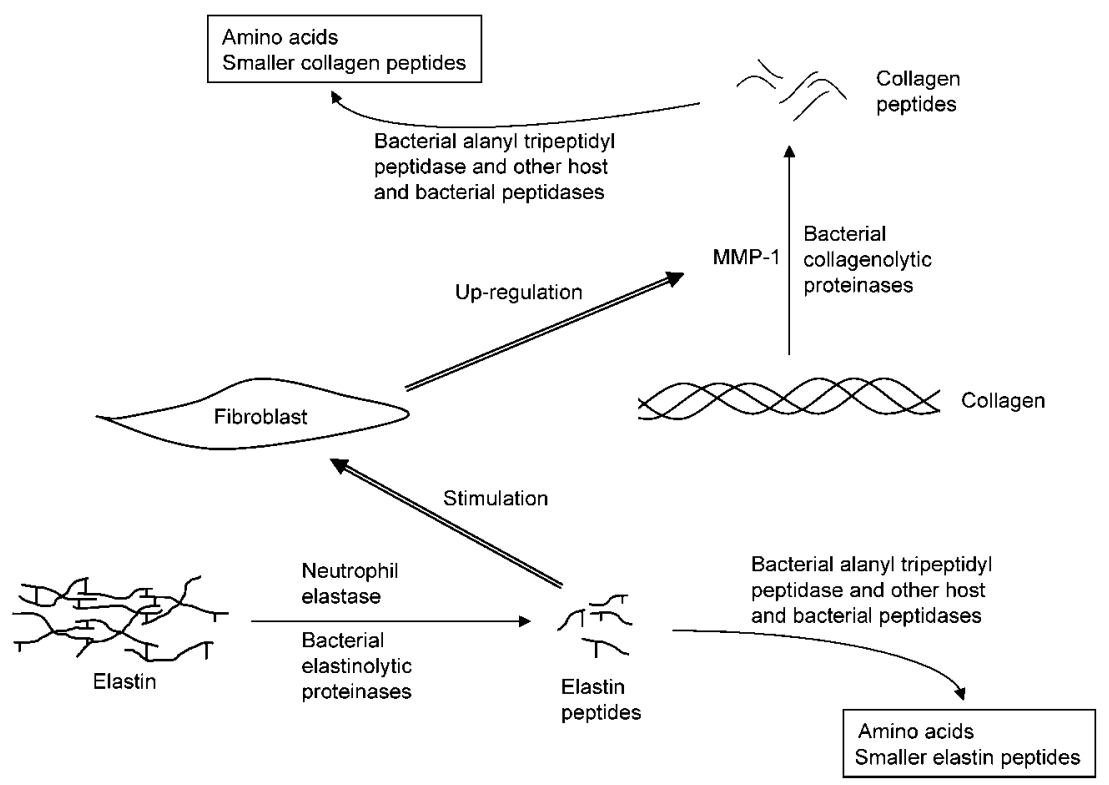

Fig. 3. Proposed scheme for combined actions of bacterial and host proteinases and peptidases in digestion of elastin and collagen in periodontal tissue. MMP-1, Matrix metalloproteinase 1. 


\section{ACKNOWLEDGEMENTS}

We thank James Travis for the use of facilities at the University of Georgia. This project was supported by grants from the American Association of Endodontists Foundation, the Office of Research, Louisiana State University School of Dentistry and the National Institute of Dental and Craniofacial Research (DE009761). This paper is dedicated to James Travis on the occasion of his $72^{\text {nd }}$ birthday.

\section{REFERENCES}

Aoyama, M., Yasuda, M., Nakachi, K., Kobamoto, N., Oku, H. \& Kato, F. (2000). Soybean-milk-coagulating activity of Bacillus pumilus derives from a serine protease. Appl Microbiol Biotechnol 53, 390-395.

Ballinger, M. D. \& Wells, J. A. (1998). Subtilisin. In Handbook of Proteolytic Enzymes, pp. 289-294. Edited by A. J. Barrett, N. D. Rawlings \& J. F. Woessner. San Diego: Academic Press.

Banerjee, C., Bustamante, C. I., Wharton, R. \& Wade, J. C. (1988), Bacillus infections in patients with cancer. Arch Intern Med 148, 1769-1774.

Bernstein, D. I., Lummus, Z. L., Santilli, G., Siskosky, J. \& Bernstein, I. L. (1995). Machine operator's lung: a hypersensitivity pneumonitis disorder associated with exposure to metalworking fluid aerosols. Chest 108, 636-641.

Beynon, R. J. \& Salvesen, G. (1989). Commercially available protease inhibitors. In Proteolytic Enzymes: A Practical Approach, pp. 242-247. Edited by R. J. Beynon \& J. S. Bond. Oxford: IRL Press.

Bickel, M. \& Cimasoni, G. (1985). The pH of human crevicular fluid measured by a new microanalytical technique. J Periodontal Res $\mathbf{2 0}$, 35-40.

Brophy, P. F. \& Knoop, F. C. (1982). Bacillus pumilus in the induction of clindamycin-associated enterocolitis in guinea pigs. Infect Immun 35, 289-295.

Callegan, M. C., Booth, M. C., Jett, B. D. \& Gilmore, M. S. (1999). Pathogenesis of gram-positive bacterial endophthalmitis. Infect Immun 67, 3348-3356.

Chavrier, C. (1990). The elastic system fibres in healthy human gingiva. Arch Oral Biol 35, 223S-225S.

Cozlin, A., Barthelemy, S., Garnotel, R., Antonicelli, F., Kaplan, H., Wornebeck, W. \& Lorimier, S. (2006). Elastolysis induces collagenolysis in a gingival lamina propria model. J Dent Res 85, 745-750.

Crouch, E. \& Bornstein, P. (1978). Characterization of a type IV procollagen synthesized by human amniotic fluid cells in culture. J Biol Chem 254, 4197-4204.

Dahlen, G. \& Moller, A. J. R. (1992). Microbiology of endodontic infections. In Contemporary Oral Microbiology and Immunology, pp. 444-475. Edited by J. Slots \& M. A. Taubman. St Louis: Mosby.

Debelle, L. \& Tamburro, A. M. (1999). Elastin: molecular description and function. Int J Biochem Cell Biol 31, 261-272.

Drobniewski, F. A. (1993). Bacillus cereus and related species. Clin Microbiol Rev 6, 324-338.

Duca, L., Debelle, L., Debret, R., Antonicelli, F., Hornebeck, W. \& Haye, B. (2002). The elastin peptides-mediated induction of procollagenase-1 production by human fibroblasts involves activation of MEK/ERK pathway via PKA- and $\mathrm{PI}_{3} \mathrm{~K}$-dependent signaling. FEBS Lett 524, 193-198.

Eley, B. M. \& Cox, S. W. (1992). Cathepsin B/L-, elastase-, tryptase-, trypsin-, and dipeptidyl peptidase IV-like activities in gingival crevicular fluid: correlation with clinical parameters in untreated chronic periodontitis patients. J Periodontal Res 27, 62-69.
Ewald, C., Kuhn, S. \& Kalff, R. (2006). Pyogenic infections of the central nervous system secondary to dental affections - a report of 6 cases. Neurosurg Rev 29, 163-167.

Fabian, J. (1970). Purification and some properties of the extracellular protease of Bacillus pumilus. Folia Microbiol (Praha) 15, 169-175.

Golabek, A. A. \& Kida, E. (2006). Tripeptidyl-peptidase I in health and disease. Biol Chem 387, 1091-1099.

Granum, P. E. \& Lund, T. (1997). Bacillus cereus and its food poisoning toxins. FEMS Microbiol Lett 157, 223-228.

Gupta, R., Beg, Q. K. \& Lorenz, P. (2002). Bacterial alkaline proteases: molecular approaches and industrial applications. Appl Microbiol Biotechnol 59, 15-32.

Harrington, D. J. (1996). Bacterial collagenases and collagendegrading enzymes and their potential role in human disease. Infect Immun 64, 1885-1891.

Helgason, E., Caugant, D. A., Olsen, I. \& Kolstø, A.-B. (2000). Genetic structure of population of Bacillus cereus and B. thuringiensis isolates associated with periodontitis and other human infections. $J$ Clin Microbiol 38, 1615-1622.

Holt, S. C. \& Ebersole, J. L. (2005). Porphyromonas gingivalis, Treponema denticola, and Tannerella forsythia: the "red complex," a prototype polybacterial pathogenic consortium in periodontitis. Periodontol 2000 38, 72-122.

Hoult, B. \& Tuxford, A. F. (1991). Toxin production by Bacillus pumilus. J Clin Pathol 44, 455-458.

Johnson, B. T., Mayo, J. A. \& Jeansonne, B. G. (1999). $\beta$-Hemolytic streptococci and other $\beta$-hemolytic organisms in apical periodontitis and severe marginal periodontitis. Endod Dent Traumatol 15, $102-108$.

Jones, L. J., Upson, R. H., Haugland, R. P., Panchuk-Voloshina, N., Zhou, M. \& Haugland, R. P. (1997). Quenched BODIPY dye-labeled casein substrates for the assay of protease activity by direct fluorescence measurement. Anal Biochem 251, 144-152.

Kakudo, S., Kikuchi, N., Kitadokoro, K., Fujiwara, T., Nakamura, E., Okamoto, H., Shin, M., Tamaki, M., Teraoka, H. \& other authors (1992). Purification, characterization, cloning, and expression of a glutamic acid-specific protease from Bacillus licheniformis ATCC 14580. J Biol Chem 267, 23782-23788.

Kato, T., Yamagata, Y., Atai, T. \& Ichishima, E. (1992). Purification of a new extracellular $90-\mathrm{kDa}$ serine proteinase with isoelectric point of 3.9 from Bacillus subtilis (natto) and elucidation of its distinct mode of action. Biosci Biotechnol Biochem 56, 1166-1168.

Kumar, C. G. (2002). Purification and characterization of a thermostable alkaline protease from alkalophilic Bacillus pumilus. Lett Appl Microbiol 34, 13-17.

Leshchinskaya, I. B., Shakirov, E. V., Itskovitch, E. L., Balaban, N. P., Mardanova, A. M., Sharipova, M. R., Blagova, E. V., Levdikov, V. M., Kuranova, I. P. \& other authors (1997). Glutamyl endopeptidase of Bacillus intermedius, strain 3-19. Purification, properties, and crystallization. Biochemistry (Mosc) 62, 903-908.

Logan, N. A. \& Berkeley, R. C. W. (1984). Identification of Bacillus strains using the API system. J Gen Microbiol 130, 1871-1882.

Loos, B. G. \& Tjoa, S. (2005). Host-derived diagnostic markers for periodontitis: do they exist in gingival crevicular fluid? Periodontol $200039,53-72$.

Makinen, K. K. \& Makinen, P.-L. (1987). Purification and properties of an extracellular collagenolytic protease produced by the human oral bacterium Bacillus cereus (strain Soc 67). J Biol Chem 262, 12488 12495.

Marsh, P. D. \& Martin, M. V. (1992). Oral Microbiology, 3rd edn. New York: Chapman \& Hall. 
McDonald, J. K. (1998). Tripeptidyl-peptidase I. In Handbook of Proteolytic Enzymes, pp. 539-540. Edited by A. J. Barrett, N. D. Rawlings \& J. F. Woessner. San Diego: Academic Press.

Miyaji, T., Otta, Y., Nakagawa, T., Watanabe, T., Niimura, Y. \& Tomizuka, N. (2006). Purification and molecular characterization of subtilisin-like alkaline protease BPP-A from Bacillus pumilus strain MS-1. Lett Appl Microbiol 42, 242-247.

Molander, A., Reit, C., Dahlen, D. \& Kvist, T. (1998). Microbiological status of root-filled teeth with apical periodontitis. Int Endod J 31, 1-7.

Nadkarni, M. A., Martin, F. E., Jacques, N. A. \& Hunter, N. (2002). Determination of bacterial load by real-time PCR using a broad-range (universal) probe and primers set. Microbiology 148, 257-266.

Nonaka, T., Fujihashi, M., Kita, A., Saeki, K., Ito, S., Horikoshi, K. \& Miki, K. (2004). The crystal structure of an oxidatively stable subtilisin-like serine protease, KP-43, with a C-terminal $\beta$-barrel domain. J Biol Chem 279, 47344-47351.

Paster, B. J., Olsen, I., Aas, J. A. \& Dewhirst, F. E. (2006). The breadth of bacterial diversity in the human periodontal pocket and other oral sites. Periodontol 2000 42, 80-87.

Priest, F. G. (1985). Synthesis and secretion of extracellular enzymes by bacilli. Microbiol Sci 2, 278-282.

Rawlings, N. D., Morton, F. R. \& Barrett, A. J. (2006). MEROPS: the peptidase database. Nucleic Acids Res 34, D270-D272 (URL: http:// merops.sanger.ac.uk)

Rinderknecht, H., Geokas, M. C., Silverman, P. \& Haverback, B. J. (1968). A new ultrasensitive method for the determination of proteolytic activity. Clin Chim Acta 21, 197-203.

Rosenbloom, J., Abrams, W. R. \& Mecham, R. (1993). Extracellular matrix 4: the elastic fiber. FASEB J 7, 1208-1218.

Socransky, S. S. (1979). Criteria for the infectious agents in dental caries and periodontal disease. J Clin Periodontol 6, 16-21.

Socransky, S. S. \& Haffajee, A. D. (1997). Microbiology of periodontal disease. In Clinical Periodontology and Implant
Dentistry, 3rd edn., pp. 138-188. Edited by J. Linde, T. Karing \& N. P. Lang. Copenhagen: Munksgaard.

Soderling, E. \& Paunio, K. U. (1981). Conditions of production and properties of the collagenolytic enzymes by two Bacillus strains from dental plaque. J Periodontal Res 16, 513-523.

Sunde, P. T., Olsen, I., Lind, P. O. \& Tronstad, L. (2000). Extraradicular infection: a methodological study. Endod Dent Traumatol 16, 84-90.

Sunde, P. T., Olsen, I., Debelian, G. J. \& Tronstad, L. (2002). Microbiology of periapical lesions refractory to endodontic therapy. J Endod 28, 304-310.

Swann, D. A. \& Sotman, S. S. (1980). The chemical composition of bovine vitreous-humour collagen fibres. Biochem J 185, 545-554.

Terleckyj, B., Willett, N. P. \& Shockman, G. D. (1975). Growth of several cariogenic strains of oral streptococci in a chemically defined medium. Infect Immun 11, 649-655.

Tran-Chau, P. T. \& Urbanek, H. (1974). Serine neutral proteinase from Bacillus pumilus as metalloenzyme. Acta Microbiol Pol B 6, 21-25.

Travis, J., Potempa, J. \& Maeda, H. (1995). Are bacterial proteinases pathogenic factors? Trends Microbiol 3, 405-407.

Travis, J., Pike, R., Imamura, T. \& Potempa, J. (1997). Porphyromonas gingivalis proteinases as virulence factors in the development of periodontitis. J Periodontal Res 32, 120-125.

Tuazon, C. U., Murray, H. W., Levy, C., Solny, M. N., Curtin, J. A. \& Sheagren, J. N. (1979). Serious infections from Bacillus sp. JAMA 241, 1137-1140.

Vann, W. F., Liu, T.-Y. \& Robbins, J. B. (1976). Bacillus pumilus polysaccharide cross-reactive with meningococcal group A polysaccharide. Infect Immun 13, 1654-1662.

Xu, L. \& Frucht, D. M. (2007). Bacillus anthracis: a multi-faceted role for anthrax lethal toxin in thwarting host immune defenses. Int $J$ Biochem Cell Biol 39, 20-24. 